\title{
A MEDIAÇÃO JUDICIAL COMO INSTRUMENTO EFETIVO NO PROCESSAMENTO E JUGAMENTO DOS PROCESSOS DE RECUPERAÇÃO E INSOLVÊNCIA EMPRESARIAL
}

\author{
JUDICIAL MEDIATION AS AN EFFECTIVE INSTRUMENT IN THE PROCESSING \\ AND JUDGMENT OF BUSINESS RECOVERY AND INSOLVENCY PROCESSES
}

\author{
José Laurindo de Souza Netto ${ }^{1}$ \\ Horácio Monteschio ${ }^{2}$ \\ Adriane Garcel $^{3}$
}

\begin{abstract}
Resumo:
O presente objetiva realizar uma abordagem sistêmica sobre a Resolução $\mathrm{n}^{\circ} 56$ do Conselho Nacional da Magistratura. A problemática está na crise de efetividade processual decorrente do fato de que a mesma recomenda a todos os magistrados responsáveis pelo processamento e julgamento dos processos de recuperação empresarial e falências, de varas especializadas ou não, que promovam, sempre que possível, nos termos da Lei no 13.105/2015 e da Lei no 13.140/2015, o uso da mediação, de forma a auxiliar a resolução de todo e qualquer conflito entre o empresário/sociedade, em recuperação ou falidos, e seus credores, fornecedores, sócios, acionistas e terceiros interessados no processo. A principal contribuição está na constatação de que, por meio da mediação, o vínculo entre as partes pode ser restabelecido ou criado e elas mesmas poderão chegar a um acordo com benefícios mútuos.
\end{abstract}

Palavras-chave: Mediação, Crise no judiciário, Teoria do conflito, Métodos adequados de resolução de conflitos, Negociação distributiva.

\begin{abstract}
The present aims to carry out a systemic approach on Resolution No. 56 of the National Council of Magistrates. The problem is in the crisis of procedural effectiveness resulting from the fact that it recommends to all magistrates responsible for the processing and judgment of business recovery and bankruptcy processes, of specialized courts or not, that promote, whenever possible, under the terms of the Law No. 13,105 / 2015 and Law No. 13,140 / 2015,

\footnotetext{
1 Mestre e Doutor pela Universidade Federal do Paraná UFPR. Pós-doutor pela Faculdade de Direito da Universidade Degli Studi di Roma La Sapienza. Com Estágio de Pós-doutorado em Portugal e Espanha. Professor de direito processual no curso de mestrado da Universidade Paranaense. UNIPAR, na União Educacional de Cascavel (UNIVEL) e na Universidade Estadual de Londrina (UEL). Autor de livros e diversos artigos jurídicos publicados em revista nacionais e internacionais. Parecerista de artigos acadêmicos, palestrante e conferencista no Brasil e no Exterior.

${ }^{2}$ Doutor em Direito pela FADISP. Mestre em Direitos da Personalidade pela UNICESUMAR. Com Estágio de Pós-doutorado pelo UNICURITIBA. Pós-Doutor em Direitos Humanos pelo Ius Gentium Conimbrigae da Faculdade de Direito da Universidade de Coimbra-Portugal. Professor de Direito Administrativo e Processo Administrativo do UNICURITIBA.

${ }^{3}$ Mestranda em Direito Empresarial e Cidadania no Centro Universitário de Curitiba - UNICURITIBA. PósGraduada em Direito Aplicado pela Escola da Magistratura do Paraná. Pós-graduada em Direito do Trabalho, Processual do Trabalho e Previdenciário pela Escola da Magistratura do Trabalho - EMATRA em parceria com o UNIBRASIL. Pós-graduada em Ministério Público - Estado Democrático de Direito pela Fundação Escola do Ministério Público do Paraná - FEMPAR em parceria com a Universidade Positivo. Licenciatura Plena em Português e Inglês. Mediadora Judicial. Servidora do Tribunal de Justiça do Estado do Paraná.
} 
the use of mediation, in order to assist in the resolution of any and all conflicts between the recovering or bankrupt businessman / society, and its creditors, suppliers, partners, shareholders and third parties interested in the process. The main contribution is in the finding that, through mediation, the bond between the parties can be reestablished or created and they themselves can reach an agreement with mutual benefits.

Keywords: Mediation, Crisis in the judiciary, Theory of conflict, Appropriate methods of conflict resolution, Distributive negotiation.

\section{INTRODUÇÃO}

Os textos processuais têm produzido, nos últimos anos, algumas relevantes inovações, especificamente no que concerna a oferta de meios alternativos para a solução dos conflitos de interesses. Trilhando o mesmo caminho o texto constitucional, já no ano de 2004, com a entrada em vigor da Emenda Constitucional $\mathrm{n}^{\mathrm{o}} 45$, denominada de "reforma do judiciário" veio a acrescer no art. $5^{\circ}$ o inc. LXXVIII, segundo o qual "a todos, no âmbito judicial e administrativo são assegurados a razoável duração do processo e os meios que garantam a celeridade de sua tramitação".

Por certo que quando existe um agrupamento de pessoas, inevitáveis serão os conflitos, porquanto podem ocorrer situações onde haverá competição pela própria sobrevivência e, então, o instinto falará mais alto.

O conflito resulta da percepção da divergência de interesses, é um fato pessoal, psicológico e social que deságua no direito apenas por opção política da organização social, variando essa intervenção do Estado conforme variam todos os demais fatores históricos, políticos e geográficos. O conflito que envolve empresas é, ainda, um fenômeno econômico, que pode gerar consequências mais amplas. Quando se trata de interesses que não podem ser individualizados (metaindividuais), a importância social do conflito é ainda maior. Os conflitos implicam em lutas entre duas ou mais pessoas acerca de valores, posição e recursos (CALMON, 2015, p. 16).

Por outro lado, a passagem pela experiência do conflito, em qualquer situação da vida, faz com que o indivíduo incorpore o aprendizado sobre aquela situação que foi objeto da desavença, conduzindo à reflexão sobre suas próprias atitudes, conduta, postura frente às frustrações do dia a dia, além das diferenças obrigatoriamente existentes entre as pessoas. Desta forma, o conflito pode não ser, totalmente, negativo. 
A cultura do conflito na sociedade moderna é preponderante na maior parte das vezes, porquanto se verifica uma enorme e interminável quantidade de conflitos, como, igualmente, o hábito predominante de deslocar ao Estado a responsabilidade de resolvê-los.

Apesar disso, também se entende que o conflito pode ser construtivo, quando se apresenta em uma discussão ou em outras formas de comunicação. Em uma cultura de cooperação, as críticas ou conflitos construtivos são aprovados e incentivados.

Por outro lado, a duração razoável do processo e os meios alternativos possuem o mesmo escopo valorativo, pois as partes envolvidas no âmbito do processo judicial querem a solução do mesmo, pois a efetividade do conflito existente, na maioria das vezes se encontra envolta em uma seara de incerteza.

Desse modo, Nagib Slabi Filho ao discorrer sobre a razoável duração do processo, aponta que a norma não deve ser observada somente como o direito ao processo em si, mas principalmente a efetividade do mesmo.

A norma garante mais que o direito de ação ou de acesso ao judiciário, mas a sua eficiência, celeridade e tempestividade. Poder-se-ia dizer que a norma declara o direito fundamental de todos à eficiente realização do processo pelo qual se leva o pedido à cognição judicial ou administrativa: é assim, direito ao processo eficiente, muito além do simples direito ao processo (2005, p. 145)

Igualmente, como ensina Franco Maziero, não sendo garantido o direito a solução integral do mérito em prazo razoável, - conforme estipula o artigo $4^{\circ}$ do Código de Processo Civil (CPC/15) e inciso LXXVIII da Constituição Federal (CF/88) - essa morosidade em se solucionar um litígio faz com que o processo deixe de ser efetivo.

Ocorre, porém, que não havendo critérios para definir o que é um processo longo ou um processo célere, a melhor forma de se averiguar a morosidade se revela naquela caracterizada pelo comportamento doloso de pelo menos um dos litigantes ou mesmo da inércia do órgão jurisdicional. Infelizmente, no Brasil, se faz presente de forma habitual os dois casos. Há aquelas partes que contam com a morosidade dos Tribunais, recorrendo, mesmo quando não há razão de ser, com o intuito eminentemente protelatório. Também não são raras as situações nas quais a morosidade decorre de inércia ou ineficácia por parte do Poder Judiciário. Não é incomum medidas liminares demorarem meses para terem uma decisão. E, nestas situações, o que se está a se referir não são as decisões denegatórias de liminar, o que permitiria, em certas ocasiões a interposição de recursos cabíveis. O que está a se referir é a inércia do Poder Judiciário de não proferir qualquer decisão, mesmo e, principalmente, nos casos em que se exige celeridade do decisium (2016. p. 71). 
A situação chega a ser tão dramática que no mês de dezembro de 2018 foi julgado pelo Superior Tribunal de Justiça (STJ) o processo mais antigo em curso no país, uma ação sobre a posse do Palácio da Guanabara (atual sede do governo do Rio de Janeiro) que tramita há mais de 123 anos em nossos Tribunais. Lembrando que o processo pode ainda não estar encerrado, sendo possível a interposição de recursos para o próprio STJ, bem como para o Supremo Tribunal Federal (STF).

O Código de Processo Civil, estabelece nos $\S 2^{\circ}$ e $\S 3^{\circ}$ do artigo 165 a definição da conciliação e da mediação no Brasil. Assim denota-se que a mediação servirá preferencialmente para os casos em que houve vínculo anterior, ou seja, em relações continuadas e que as próprias partes possam encontrar a solução para a o conflito.

A mediação vista pela abordagem transformativa concebe o instituto como um instrumento de vivência que pode propiciar a oportunidade para as partes envolvidas no conflito desenvolverem a capacitação (autodeterminação) e a empatia (reconhecimento). Nesse sentido, Joseph. P. Folger e Robert A. Baruch Bush, explicitam que, um enfoque na capacitação significa que o terceiro observa pontos no processo em que as partes têm oportunidades de obter uma maior clareza em relação a seus objetivos, recursos, opções e preferências - e, “então, trabalha com essas oportunidades de modo a apoiar os processos das próprias partes de esclarecer e deliberar decisões.” (1999, p. 87)

Um enfoque sobre o reconhecimento significa que o terceiro observa os pontos e que os disputantes enfrentam a escolha de quanta consideração dar à perspectiva, ponto de vista ou experiências do outro- e, então, trabalha para apoiar os esforços de tomada de decisão e de perspectiva das próprias partes em relação a esses pontos. É nesse sentido que a mediação é potencialmente transformativa; ela oferece aos indivíduos a oportunidade de reforçar e integrar suas capacidades de autodeterminação e responsividade aos outros.

Desta forma, cabe ressaltar o fato que vem a reforçar a possibilidade de meios alternativos para a composição de conflitos, inclusive, colocando em dúvida o até então inexpugnável dogma da indisponibilidade do interesse público, presente no direito administrativo pátrio. Neste pensar cita-se a alteração produzida no Decreto Lei ${ }^{\circ}$ 3.365/41 produzida pela Lei $\mathrm{n}^{\circ}$ 13.867, de 2019, a qual passa admitir a mediação nos processos envolvendo a desapropriação feita pelo poder público, ou seja, as partes podem formular concessões reciprocas com o intuito de compor o conflito envolvendo as partes.

No mesmo sentido virtuoso a Resolução $n^{\circ} 56$ do Conselho Nacional da Magistratura, a qual Inicialmente irá analisar a crise de efetividade processual decorrente do fato de que a mesma recomenda a todos os magistrados responsáveis pelo processamento e 
julgamento dos processos de recuperação empresarial e falências, de varas especializadas ou não, que promovam, sempre que possível, nos termos da Lei $\mathrm{n}^{\circ} 13.105 / 2015$ e da Lei $\mathrm{n}^{\circ}$ 13.140/2015, o uso da mediação, de forma a auxiliar a resolução de todo e qualquer conflito entre o empresário/sociedade, em recuperação ou falidos, e seus credores, fornecedores, sócios, acionistas e terceiros interessados no processo.

Por finalmente é importante citar a doutrina de Silvio de Salvo Venosa utiliza o direito comparado para apresentar essa possibilidade:

No direito chinês, antes de se chegar a um processo judicial, tentam-se todas as formas de conciliação, pois existem muitos grupos sociais dispostos a conciliar os antagonistas, como os municípios e as próprias famílias. Mesmo quando já se conseguiu uma decisão favorável em Juízo, reluta-se em executá-la; quando executada, procede-se de forma que prejudique o adversário o mínimo possível. Esses são os pensamentos tradicionais chineses, de acordo com a doutrina de Confúcio, tão distantes de nosso entendimento ocidental (VENOSA, 2012. p. 70).

Curiosamente, Boaventura de Sousa Santos já desenhava a crise do judiciário em 1999 e afirmava que mesmo as pessoas naturalmente buscando junto ao Estado a resolução de seus litígios, outros mecanismos podem ser utilizados de forma mais eficiente, célere e econômica.

Em primeiro lugar, de um ponto de vista sociológico, o Estado contemporâneo não tem o monopólio da produção e distribuição do direito. Sendo embora o direito estatal o modo de juridicidade dominante, ele coexiste na sociedade com outros modos de juridicidade, outros direitos que com ele se articulam de modos diversos. Este conjunto de articulações e interrelações (sic) entre vários modos de produção do direito constitui o que designo por formação jurídica. Em segundo lugar, o relativo declínio da litigiosidade civil, londe (sic) de ser início de diminuição da conflitualidade social e jurídica, é antes o resultado do desvio dessa conflitualidade para outros mecanismos de resolução, informais, mais baratos e expeditos, existentes na sociedade. [...] As reformas que visam a criação de alternativas constituem hoje uma das áreas de maior inovação na política judiciária. Elas visam criar, em paralelo à administração da justiça convencional, novos mecanismos de resolução de litígios cujos traços constitutivos têm grandes semelhanças com os originalmente estudados pela antropologia e pela sociologia do direito, ou seja, instituições leves, relativa ou totalmente desprofissionalizadas (sic), por vezes impedindo mesmo a presença de advogados, de utilização barata, se não mesmo gratuita, localizados de modo a maximizar o acesso aos seus serviços, operando por via expedita e pouco regulada, com vista à obtenção de soluções mediadas entre as partes (1999. p. 154). 
Diante dessa realidade apresentada, o legislador ao elaborar o CPC/15 trouxe logo no parágrafo $3^{\circ}$ do seu artigo $3^{\circ}$ o incentivo para a utilização de métodos de solução adequados de conflitos como a mediação e conciliação, os quais devem ser estimulados por todos os sujeitos do processo.

\section{MEDIAÇÃ̃O}

Uma vez compreendido que o conflito é inerente à condição humana em sociedade $\mathrm{e}$ que não há como expurgá-lo e, ainda considerando a crise do Judiciário - especialmente acarretada a falta de pessoal para que se possa solucionar em tempo hábil a quantidade absurda de processos - o legislador brilhantemente enfatizou a utilização de meios adequados de solução de conflito no $\mathrm{CPC} / 15$.

Uma disputa firmada entre adversários, como é o caso dos conflitos judiciais, normalmente a possibilidade de comunicação já está demasiadamente perdida e a cada informação externalizada, a mesma será recebida como um ataque e, ao invés de se expor os reais motivos (e tentar solucionar o litígio), simplesmente será preparada uma nova argumentação para rebater o que lhe foi dito.

\footnotetext{
O que geralmente ocorre no conflito processado com enfoque adversarial é a hipertrofia do argumento unilateral, quase não importando o que o outro fala ou escreve. Por isso mesmo, enquanto um se expressa, o outro já prepara uma nova argumentação. Ao identificarem que não estão sendo entendidas, escutadas, lidas, as partes se exaltam e dramatizam, polarizando ainda mais as posições. A solução transformadora do conflito depende do reconhecimento das diferenças e da identificação dos interesses comuns e contraditórios, subjacentes, pois a relação interpessoal funda-se em alguma expectativa, valor ou interesse comum. [...] $\mathrm{O}$ conflito, quando bem conduzido, pode resultar em mudanças positivas e novas oportunidades de ganho mútuo (VASCONCELOS, 2008, p. 20).
}

Segundo o CNJ (2019) a mediação é uma negociação integrativa que será intermediada por um terceiro imparcial (mediador) objetivando exatamente mudanças positivas e ganhos mútuos. Preferencialmente, deverá ocorrer em casos que já exista uma relação anterior entre as partes, a fim de que as mesmas possam compreender os pontos e interesses que ocasionaram o conflito para que, uma vez restaurada a comunicação, criem soluções em comum acordo que beneficiem ambos.

Desta forma, observa-se que as proposições e execuções das Políticas Públicas devem ser embasadas pelo instituto da participação do cidadão e pelo princípio da 
transparência, o que equivale a dizer que o cidadão não deve ser visto somente o destinatário passivo da Política Pública e sim como sujeito ativo que participa da Administração Pública e possui acesso à informação. Nesse sentido, esclarece Gianpaolo Poggio Smanio:

A participação acarreta necessariamente a cooperação entre Estado e sociedade, bem como entre os próprios cidadãos, criando um círculo virtuoso de legitimidade para as Políticas Públicas, porque é uma garantia de que efetivamente as necessidades da população estão em decisão e execução. [...] Participação e Transparência são princípios derivados do Princípio Democrático o Estado, de forma que as Políticas Públicas estão estreitamente relacionadas com a democracia praticada (2013, p. 10-11).

\subsection{A MEDIAÇÃO E A ABORDAGEM TRANSFORMATIVA}

A autocomposição é um meio de resolver conflitos pela decisão consensual das partes, onde não há imposição destas e nem de um terceiro imparcial. Na autocomposição, há mecanismos que possibilitam a resolução do conflito pelo consenso.

Como fora mencionado, o Brasil adotou a autocomposição por meio da conciliação e da mediação. Petronio Calmon define a mediação ao ilustrar que, Mediação é a intervenção de um terceiro imparcial na negociação entre os envolvidos no conflito, facilitando o diálogo ou incentivando o diálogo inexistente, "com vistas a que as próprias partes encontrem a melhor forma de acomodar ambos os interesses, resolvendo não somente o conflito, mas também a própria relação antes desgastada, permitindo sua continuidade pacífica" (CALMON, 2008.p. 103)

Por sua vez para Célia Regina Zapparolli e Mônica Coelho Krähenbühl o instrumento da mediação recebe os seguintes contornos:

A mediação é instrumento devotado á solução dos conflitos intersubjetivos em relações continuadas, nas mais diversas áreas e situações, sendo aplicável, também, aos contextos de violências e de crimes (Ex: Lei n. 9.099/95 e 11.340/06). Ela não faz as vezes nem vem substituir a psicoterapia, a psicanálise, pois não se destina à solução dos conflitos intrapsíquicos. Apesar disso, quando transformativa, pode ter efeitos terapêuticos, gerando mudanças de segunda ordem (ZAPPAROLLI, 2012. p. 38)

Dessa forma, esta pesquisa entende que há uma aproximação entre a "mediação transformativa" proposta com o princípio do empoderamento conceituado conforme disposto 
na Resolução $n^{\circ} 125 / 10$, a qual o Conselho Nacional de Justiça organizar programa com o objetivo de promover ações de incentivo à autocomposição de litígios e à pacificação social por meio da conciliação e da mediação. O programa contemplado pela citada Resolução será implementado com a participação de rede constituída por todos os órgãos do Poder Judiciário e por entidades públicas e privadas parceiras, inclusive universidades e instituições de ensino. Para tanto, o Conselho Nacional de Justiça busca estabelecer diretrizes para implementação da política pública de tratamento adequado de conflitos a serem observadas pelos Tribunais.

Sendo uma das obrigações dos Conselho Nacional de Justiça qualificar todos os conciliadores, mediadores e outros especialistas em métodos consensuais de solução de conflitos deverão submeter-se a aperfeiçoamento permanente e a avaliação do usuário.

E por isto, este necessita ser explorado para melhor embasar a função do mediador como um agente que pode propiciar a transformação dos indivíduos que atuam no meio social, ao oportunizar espaços de vivências que ofereçam o exercício da autodeterminação e do reconhecimento, que gerará o empoderamento das partes. E isto pode contribuir para a prevenção de conflitos e trazer pacificação social.

\section{FUNÇÃO SOCIAL DA EMPRESA}

Dentro do contexto do Estado Democrático de Direito brasileiro, o empresário não pode ser visto como pessoa desvinculada da realidade social e econômica. Sua dimensão jurídica não é isolável das relações humanas em sociedade. Dessa forma e, pelo fato de o empresário ser dependente da comunidade, não se mostra racional que o mesmo se isole em uma fortaleza inexpugnável, eis que a sociedade influenciará no sucesso da atividade empresarial, pois também é responsável pela circulação de riquezas.

A respeito da função social da empresa perante a comunidade, observa Luiz Antônio Ramalho Zanoti:

Há um recíproco dever de fidelidade entre os sócios e a sociedade. O exercício do direito societário não é tão amplo a ponto de o sócio visar a interesses pessoais, em detrimento dos interesses sociais. Quem decide pela opção de investir seus recursos financeiros ou materiais numa atividade empresarial, na expectativa de que ela lhe proporcione lucros em forma de dividendos, deve ter conta que essa organização tem uma responsabilidade social para com os empregados, consumidores, meio ambiente, fornecedores, comunidade e o Estado, e que esse sócio tem também as mesmas responsabilidades (ZANOTI, 2009, p. 181). 
Então, a atividade empresarial, além de buscar o lucro, deve se preocupar com a comunidade em que está inserida. Destarte, é imprescindível que o objetivo econômico do empresário seja harmonizado com a necessidade de respeito à dignidade da pessoa humana. Neste sentido, Ana Frazão de Azevedo Lopes assevera que:

O esforço isolado do Estado para assegurar a justiça social é inócuo se a sociedade e os indivíduos que a compõem não assumirem a sua responsabilidade e a efetiva participação no processo. A função social da propriedade e da empresa não deixa de ser uma tentativa de inserir a solidariedade nas relações horizontais entre os indivíduos, transformando-os em responsáveis pela efetiva realização do projeto de uma sociedade de membros autônomos e iguais, inclusive no que diz respeito à redução das desigualdades sociais (LOPES, 2006.p. 253).

Se o empresário se isolar da comunidade, sem se preocupar com os efeitos da ausência do exercício da função social, deixará de garantir uma forma de prolongar, no tempo, suas atividades. Se ele planeja expandir ou manter sua atividade lucrativa, deve colaborar para a promoção do bem de todos, eis que, para um desenvolvimento sustentável, deve preservar as coisas nas quais se sustenta o desenvolvimento. É neste sentido a observação de Luiz Antônio Ramalho Zanoti, que sustenta:

A função social das corporações está ligada à sustentabilidade. Embora seja admissível que as corporações pugnem pela contabilização de lucros decorrentes de suas atividades empresariais, é imprescindível que este objetivo econômico seja conciliado com a necessidade de se preservar o meio ambiente e de se valorizar a dignidade da pessoa humana, até mesmo como forma de garantir a longevidade e a expansão de seus próprios negócios (ZANOT, p. 180).

No mesmo sentido, Ana Frazão de Azevedo Lopes observa que:

O equilíbrio entre a liberdade empresarial e o igual direito à liberdade dos demais membros da sociedade é extremamente delicado e envolve a questão da justiça social. Esta, por sua vez, não tem como ser reduzida a fórmulas fechadas e que sejam insensíveis ao processo democrático e ao contexto social e histórico em que é analisada (LOPES, p. 279.).

Sobre os interesses da comunidade a respeito da empresa, observa Sérgio Botrel:

A comunidade, por fim, tem interesse, sob o ponto de vista legal: no cumprimento das obrigações fiscais e no cumprimento da legislação; sob o ponto de vista social: na contribuição positiva para o desenvolvimento local 
e regional; no que respeita ao meio ambiente, na preservação dos recursos naturais renováveis e não renováveis (2009. p. 127).

Decorre da função social da empresa a necessidade de que o empresário não se aproprie, de forma isolada, das benfeitorias geradas pela atividade econômica. Esses benefícios devem ser repartidos, com toda a comunidade. A necessidade dessa distribuição de ganhos também decorre do aumento da exigência da comunidade frente aos empresários, detentores de grande poder econômico e com enorme capacidade de afetação na sociedade em que estão inseridos.

Destarte, um empresário que se afasta da função social de sua atividade, necessariamente se afasta da comunidade. Neste sentido de preservação da empresa o Conselho Nacional de Justiça elaborou a Resolução $n^{\circ} 56$ com o claro intuito de preservar a empresa.

\section{RESOLUÇÃO Nº 56 DO CONSELHO NACIONAL DA MAGISTRATURA}

O Conselho Nacional de Justiça o desenvolvimento de políticas judiciárias que promovam efetividade e unidade ao Poder Judiciário, orientadas para os valores de justiça e paz social, com fundamento na Portaria $\mathrm{n}^{\mathrm{o}}$ 162, de 19 de dezembro de 2018, o Grupo de Trabalho para debater e sugerir medidas voltadas à modernização e à efetividade da atuação do Poder Judiciário nos processos de recuperação empresarial e de falência. Desta forma, em face das atividades de modernização e efetivação da atuação do Poder Judiciário a mediação e outros métodos de solução consensual de conflitos devem ser estimulados pelos juízes, conforme disposto no art. $3^{\circ}$, parágrafo $3^{\circ}$, e no art. 334 do Código de Processo Civil, consolidado na Lei nº 13.105, de 16 de março o de 2015.

Com a entrada em vigora da Lei $\mathrm{n}^{\mathrm{o}} 13.140$, de 26 de junho de o 2015, a qual regulamentou, no ordenamento jurídico, o procedimento de mediação, judicial e extrajudicial, como meio de solução de controvérsias, bem como com o objetivo de ofertar novos contornos para a solução dos conflitos envolvendo a recuperação judicial nos termos do art. 47 da Lei n 11.101, de 9 de fevereiro de o 2005, a qual é viabilizar a superação da situação de crise econômico-financeira do devedor, a fim de permitir a manutenção da fonte produtora, do emprego dos trabalhadores e dos interesses dos credores, preservando a empresa, sua função social e o estímulo à atividade econômica. 
Dentro do panorama valorativo envolvendo a recuperação extrajudicial objetiva também soerguer a empresa em crise, com isso para evitar que a falência visa preservar e otimizar a utilização produtiva dos bens, ativos e recursos produtivos, inclusive os intangíveis, da empresa, como previsto no art. 75 da Lei ${ }^{\circ} 11.101 / 2005$.

Por sua vez o inteiro teor do Enunciado $n^{\circ} 45$, aprovado na I Jornada de Prevenção e Solução Extrajudicial de Litígios, iniciativa promovida pelo Conselho da Justiça Federal alinhada ao entendimento de que "a mediação e conciliação são compatíveis com a recuperação judicial, a extrajudicial e a falência do empresário e da sociedade empresária, bem como em casos de superendividamento, observadas as restrições legais", bem como diante da complexidade dos processos de recuperação judicial que abrangem interesses de múltiplas partes e dos interesses de todos, o consenso e a paz social, aliado aos diversos casos exitosos de procedimentos de mediação instaurados em processos de insolvência em curso perante as varas especializadas dos Estados de São Paulo e do Rio de Janeiro, revelando que, na prática, a criação de um ambiente seguro e propício para negociação e acordos tem se mostrado altamente eficaz.

Como conclusão desses argumentos o Conselho Nacional de Justiça acabou por contemplar a recomendação feita a todos os magistrados responsáveis pelo processamento e julgamento dos processos de recuperação empresarial e falências, de varas especializadas ou não, que promovam, sempre que possível, nos termos da Lei $n^{\circ} 13.105 / 2015$ e da Lei $n^{\circ}$ 13.140/2015, o uso da mediação, de forma a auxiliar a resolução de todo e qualquer conflito entre o empresário/sociedade, em recuperação ou falidos, e seus credores, fornecedores, sócios, acionistas e terceiros interessados no processo.

Assim sendo a mediação pode ser implementada nas seguintes hipóteses envolvendo os incidentes de verificação de crédito, permitindo que devedor e credores cheguem a um acordo quanto ao valor do crédito e escolham um dos critérios legalmente aceitos para atribuição de valores aos bens gravados com direito real de garantia, otimizando o trabalho do Poder Judiciário e conferindo celeridade à elaboração do Quadro Geral de Credores.

No mesmo sentido, para auxiliar na negociação de um plano de recuperação judicial, aumentando suas chances de aprovação pela Assembleia Geral de Credores sem a necessidade de sucessivas suspensões da assembleia, para que devedor e credores possam pactuar, em conjunto, nos casos de consolidação processual, se haverá também consolidação substancial, com o intuído de solucionar disputas entre os sócios/acionistas do devedor.

Outra possibilidade de admissão da mediação é possível que a mesma venha a ser utilizadas em casos de concessionárias/permissionárias de serviços públicos e órgãos 
reguladores, para pactuar acerca da participação dos entes reguladores no processo e, nas diversas situações que envolvam credores não sujeitos à recuperação, nos termos do $\S 3^{\circ}$ do art. 49 da Lei ${ }^{\circ}$ 11.101/2005, ou demais credores extraconcursais.

Por sua vez é vedada a utilização da mediação acerca da classificação dos créditos. Ademais o acordo obtido por meio de mediação não dispensa a deliberação por Assembleia Geral de Credores nas hipóteses exigidas por lei, nem afasta o controle de legalidade a ser exercido pelo magistrado por ocasião da respectiva homologação.

Sem prejuízo da mediação extrajudicial, o magistrado poderá, a qualquer tempo do processo, nomear mediador, a requerimento do devedor, do administrador judicial ou de credores que detenham percentual relevante dos créditos do devedor, para quaisquer questões atinentes à coletividade de credores, ou a requerimento do devedor, do administrador judicial e de credor individual, para os casos de verificação de créditos.

Destarte o mediador poderá ser nomeado de ofício nos casos em que o magistrado entender útil para que o processo se desenvolva de maneira mais eficiente. O qual para exercer a função, além da qualificação para atuar como mediador, o profissional deverá ter experiência em processos de insolvência e em negociações complexas com múltiplas partes, podendo tais requisitos serem dispensados na hipótese de nomeação por consenso entre as partes ou de nomeação de um comediador que possua referida experiência.

Outrossim, o autor do requerimento para instauração da mediação poderá indicar até três nomes para exercer a função de mediador, cabendo à contraparte, caso aceite, escolher um dos nomes, que deverá ser nomeado pelo magistrado. Na hipótese de serem múltiplas as contrapartes, o magistrado deverá verificar se há consenso sobre um dos nomes indicados pelo requerente, fazendo a respectiva nomeação.

Diante da ausência de consenso entre as partes na escolha do mediador, o magistrado deverá oficiar a um Centro de Mediação que tenha lista de profissionais habilitados a exercer a função nos processos de que trata esta Recomendação para que indique um mediador apto para atuar em tais processos. Caso contrário, em não havendo Centro de Mediação ou mesmo diante do dissenso entre as partes caberá ao magistrado fazer a nomeação a sua livre escolha, podendo acolher um dos nomes indicados pelas partes.

Os impedimentos ou suspeições envolvendo a pessoa do mediador, em razão da sua inocorrência, o mediador que aceitar a sua designação poderá sugerir às partes e ao magistrado, conforme o caso, a nomeação de um ou mais comediadores e/ou a consulta a técnicos especializados, sempre em benefício do bom desenvolvimento da mediação, 
considerando a natureza e a complexidade do caso ou o número de procedimentos de verificação de créditos em que deverá atuar.

O mediador exercerá suas funções com autonomia, inclusive quanto aos procedimentos a serem adotados nas sessões de mediação, devendo respeitar a legislação e padrões éticos, além de manter a confidencialidade das informações a que tiver acesso e que não sejam públicas.

Nas mediações plurilaterais, os honorários do mediador deverão ser custeados pelo devedor e, nas mediações bilaterais, deverão ser repartidos entre as partes, salvo, em qualquer caso, se as partes pactuarem de forma diversa.

Não serão devidos honorários ao mediador na realização da primeira sessão de mediação, caso essa se revele desde logo inviável, cabendo ao devedor, nessa hipótese, reembolsar o mediador pelas despesas incorridas e previamente aprovadas.

A mediação poderá ser presencial ou o on-line por meio de plataformas digitais, quando justificada a utilidade ou necessidade, especialmente nos casos em que haja elevado número de participantes e credores sediados no exterior, cabendo ao mediador ou ao Centro de Mediação prover os meios para a sua realização.

A mediação deverá ser incentivada em qualquer grau de jurisdição, inclusive no âmbito dos Tribunais Superiores, e não implica a suspensão ou interrupção do processo e dos prazos previstos na Lei ${ }^{\circ} 11.101 / 2005$, salvo consenso entre as partes ou deliberação judicial.

Os magistrados não deverão atuar como mediadores, sendo vedada ao administrador judicial a cumulação das funções de administrador e mediador. A possibilidade de realização de mediação não impede que o magistrado ou o administrador judicial conduzam tentativas de conciliação e negociação.

\section{CONCLUSÕES}

Pelas razões acima expostos, percebe-se um grande esforço por parte do Conselho Nacional de Justiça - CNJ, em encontrar meios de proporcionar mais efetividade ao processo judicial, aumentando a satisfação do jurisdicionado e o incentivo a uma resolução construída pelas próprias partes, a fim de que o mesmo conflito não volte a bater nas portas do Poder Judiciário, buscando o cumprimento ao princípio da eficiência, previsto constitucionalmente e, para tanto, foi editada a Resolução 125/2010/CNJ, dando início oficial a tal abordagem no sistema judicial no Brasil, bem como da Resolução 56. 
Desta forma, considerando o advento do Novo Código de Processo Civil - Lei ${ }^{\circ}$ 13.105/2015, bem como sobre a obrigatoriedade da audiência conciliatória na fase inicial do processo, entende-se que a novel regra irá proporcionar às partes um encontro, a fim de que possam conversar sobre o objeto da lide e, quem sabe, resolvê-la na oportunidade. Também entende-se como primordial a necessidade da mudança de paradigma para a efetiva resolução dos conflitos, que deve iniciar já nos bancos acadêmicos, para que os bacharéis em Direito sejam orientados não somente sobre as regras processuais, mas também sobre a necessidade de se repensar o processo sob o enfoque da conciliação.

A justificativa essencial a edição da Resolução $n^{\circ} 56$ se encontra fundamentada na preservação da função social da empresa, a qual tem como fundamento e desdobramentos o desenvolvimento nacional, do emprego, da geração de renda, do recolhimento de tributos entre outros, razões mais do que suficientes para sua edição e efetivação.

\section{REFERÊNCIAS}

BOTREL, Sérgio. Direito societário constitucional: uma proposta de leitura constitucional do direito societário. São Paulo: Atlas, 2009.

BRASIL. Decreto Lei no 3365/41.

CALMON, Petrônio. Fundamentos da Mediação e da Conciliação. Rio de Janeiro: Forense, 2008.

CRUZ, Luiz Henrique; MACIEL-LIMA, Sandra; SOUZA-LIMA, José Edmilson de. MEDIAÇÃO EXTRAJUDICIAL E EFETIVIDADE DA JUSTIÇA: APLICAÇÃO NOS CASOS DE DESASTRES AMBIENTAIS. Percurso, [S.1.], v. 4, n. 31, p. 23 - 32, dez. 2019. ISSN 2316-7521. Disponível em: <http://revista.unicuritiba.edu.br/index.php/percurso/article/view/3699/371372064>. Acesso em: 25 abr. 2020.

DIAS, Luciano Souto; FARIA, Kamila Cardoso. A MEDIAÇÃO E A CONCILIAÇÃO NO CONTEXTO DO NOVO CÓDIGO DE PROCESSO CIVIL DE 2015. Revista Jurídica, [S.1.], v. 3, n. 44, p. 597 - 630, fev. 2017. ISSN 2316-753X. Disponível em: <http://revista.unicuritiba.edu.br/index.php/RevJur/article/view/1881/1251>. Acesso em: 25 abr. 2020. doi:http://dx.doi.org/10.21902/revistajur.2316-753X.v3i44.1881.

FOLGER, Joseph. P.;BUSH, Robert A. Baruch. Mediação transformativa e intervenção de terceiros: as marcas registradas de um profissional transformador. In: SCHNITMAN, Dora Fried; LITTLE JOHN, Stephen. Novos paradigmas em mediação (Org). Porto Alegre: Artmed, 1999.

LIMA, Priscila Luciene de; FREITAS, Gelcymar Santos dos Santos de; NETO, Alcelyr Valle da Costa. A IMPORTÂNCIA DO TRABALHO COM CONSTELAÇÕES NAS AUDIÊNCIAS DE MEDIAÇÃO. Percurso, [S.1.], v. 2, n. 25, p. 20 - 26, dez. 2018. ISSN 2316-7521. 
<http://revista.unicuritiba.edu.br/index.php/percurso/article/view/3093/371371625>. Acesso em: 25 abr. 2020.

MAZIERO, Franco Giovanni Mattedi. Manual da advocacia colaborativa. Rio de Janeiro: Lumen Juris, 2016.

VASCONCELOS, Carlos Eduardo de. Mediação de conflitos e práticas restaurativas. São Paulo: Método, 2008.

VENOSA, Sílvio de Salvo. Direito Civil - Parte Geral. Vol. 1. 12. ed. São Paulo: Atlas, 2012.

SANTOS, Boaventura de Sousa. Pela mão de Alice. O social e o político na pósmodernidade. 7. ed. Porto: Afrontamentos, 1999.

SLAIBI FILHO, Nagib. Reforma da Justiça. Rio de Janeiro: Impetus, 2005.

SMANIO, Gianpaolo Poggio. Legitimidade jurídica das políticas públicas: a efetivação da cidadania. In: SMANIO, Gianpaolo Poggio; BERTOLIN, Patricia Tuma (Org.). O direito e as políticas públicas no Brasil. São Paulo: Atlas, 2013.

ZANOTI, Luiz Antônio Ramalho Zanoti. Empresa na ordem econômica: princípios e função social. Curitiba: Juruá, 2009.

ZAPPAROLLI, Célia Regina; KRÄHENBÜHL, Mônica Coelho. Negociação, mediação, conciliação, facilitação assisitida, prevenção, gestão de crises nos sistemas e suas técnicas. São Paulo: LTr, 2012. 